\title{
Communities of practice in academia: Testing a quantitative model
}

\author{
Nicolae Nistor ${ }^{\mathrm{a}, \mathrm{b}, \mathrm{c}, *}$, Frank Fischer ${ }^{\mathrm{a}, 1}$ \\ a Faculty of Psychology and Educational Sciences, Ludwig-Maximilians-Universität, Leopoldstr. 13, D-80802 München, Germany \\ ${ }^{\mathrm{b}}$ Department of Learning Science, Graduate School of Education, Hiroshima University, 1-1-1, Kagamiyama, Higashi-Hiroshima, 739-8524 Japan \\ ${ }^{\mathrm{c}}$ Richard W. Riley College of Education and Leadership, Walden University, 100 Washington Avenue South, Suite 900, Minneapolis, MN 55401, USA
}

\section{A R T I C L E I N F O}

\section{Article history:}

Received 22 August 2011

Received in revised form 21 May 2012

Accepted 24 May 2012

Available online 28 June 2012

\section{Keywords:}

Communities of practice

Participation

Quantitative research

Workplace learning

University staff

\begin{abstract}
A B S T R A C T
Up to now, the relationships among the fundamental notions of communities of practice (CoPs), i.e. knowledge, participation, identity, and artifact development have been based mainly on results from qualitative studies; they are not yet sufficiently based on quantitative evidence. Starting from a literature review, we formulate a quantitative, causal model of CoPs that describes these variables in the context of academic communities, and aim to validate this model in two academic CoPs with a total of $\mathrm{N}=208$ participants. A cluster analysis classifies the participants into clusters that are in line with the core-periphery structure known from previous qualitative studies. A regression analysis provides evidence for the hypothesized model on the basis of quantitative data. Suggested directions for future research are to focus on factors that determine CoP participants' contributions to artifact development and on approaches to automated monitoring of virtual CoPs.
\end{abstract}

(c) 2012 Elsevier Ltd. All rights reserved.

\section{Introduction}

Communities of practice (CoPs) are groups of people sharing goals, activities, and experiences in the context of a given practice (Lave \& Wenger, 1991; Wenger, 1999). Participation in CoPs is assumed to lead to the accumulation of experience, stimulation of the social construction of knowledge, and the development of expertise (Bereiter, 2002; Boylan, 2010; Engeström \& Sannino, 2010; Fuller, Unwin, Felstead, Jewson, \& Kakavelakis, 2007; Lave \& Wenger, 1991; Paavola, Lipponen, \& Hakkarainen, 2004; Tobbell, O'Donnell, \& Zammit, 2010; Wenger, 1999). In contrast to the norm for schools, observable teaching (e.g., lecturing) in CoPs is rare. Nevertheless, the basic phenomenon in CoPs appears to be learning, and the potential curriculum is defined by the community practice (Lave \& Wenger, 1991, p. 92).

The theory of situated learning is primarily founded on examples that best serve to illustrate the meaning of the notions of community and practice. A prominent example is that of Mayan midwives from Yucatan, who allow younger women to observe their activities when they are attending a laboring mother (Jordan, 1989; Lave \& Wenger, 1991, p. 67). In a further example, teachers, together with pupils and pupils' parents, carry out the daily activities of a Canadian village school and at the same time prevent the school from being closed due to organizational difficulties (Roth \& Lee, 2006). Of a similar nature - and of particular relevance for this study - are the numerous communities founded in schools (e.g., Bonsen \& Rolff, 2006), universities (e.g., Brown, 2001; Rovai, 2002; Thompson \& MacDonald, 2005; Tobbell et al., 2010; Visscher \& Witziers, 2004) and research institutions (Kienle \& Wessner, 2006). By examining these examples, we observe that CoP literature is based mainly on qualitative research, with few quantitative studies about learning and development in this context (e.g., Kienle \& Wessner, 2006; Stewart, 2010; Visscher \& Witziers, 2004). In particular, the relationships among the fundamental notions of CoPs are mainly based on qualitative studies and not sufficiently backed up with quantitative evidence. Therefore, the aim of this paper is to propose a quantitative model of CoPs that describes the relationships

\footnotetext{
* Corresponding author at: Faculty of Psychology and Educational Sciences, Ludwig-Maximilians-Universität, Leopoldstr. 13, D-80802 München, Germany. Tel.: + 49892180 5284, + 8182424 68892; fax: + 4989218099 5284, + 818242468892.

E-mail address: nic.nistor@uni-muenchen.de (N. Nistor).

1 Tel.: + $498921805284,+8182424$ 68892; fax: + 4989218099 5284, + 818242468892.
} 
among the main notions (knowledge and experience, participation, expert status, and cultural artifact development). We begin with an examination of research literature to define the central variables and to integrate them into a causal model. Then we verify this model empirically in the context of academic CoPs.

\section{The central variables of CoPs}

\subsection{Expertise in CoPs}

Etienne Wenger (1999, p. 4) builds the theory of situated learning starting from the premise that "knowledge is a matter of competence with respect to valued enterprises - such as singing in tune, discovering scientific facts, fixing machines, writing poetry, being convivial, growing up as a boy or a girl, and so forth". So far, Wenger's view of knowledge corresponds to the generally accepted definition of expertise as advanced and reproducible knowledge and skills in a specific domain. Also, Wenger's view of learning by experience ("competence may drive experience; experience may drive competence"; Wenger, 1999, p. 138) implies that experience is correlated with domain knowledge and both have an impact on participation.

In this sense, expertise is fundamentally an individual characteristic of the expert. This view is endorsed by the possibility of having objective criteria that define the expert and expertise. A second view on expertise, discussed in Section 2.3, "expert status", implies the existence of a social context in which experts are recognized as such. In the following discussion, we regard the social recognition of experts as a (direct or indirect) consequence of their expertise.

In an attempt to formulate a quantitative model of CoPs, we regard expertise in the sense mentioned above: an independent variable with the components domain knowledge and experience. Expertise is often acquired in the CoP, as Lave and Wenger (1991) claim, but it can be brought from outside as well, such as by expert newcomers (Fuller, 2007). Further, we regard expertise as a determinant of participation in CoPs.

\subsection{Participation}

Wenger (1999, p. 4) defines participation as a notion that "refers not just to local events of engagement in certain activities with certain people, but to a more encompassing process of being active participants in the practices of social communities and constructing identities in relation to these communities. Participating in a playground clique or in a work team, for instance, is both a kind of action and a form of belonging. Such participation shapes not only what we do, but also who we are and how we interpret what we do." This definition is complemented by the numerous examples of CoPs described in the research literature (e.g., Bonsen \& Rolff, 2006; Brown, 2001; Jordan, 1989; Kienle \& Wessner, 2006; Lave \& Wenger, 1991; Rovai, 2002; Thompson \& MacDonald, 2005), which reveal also differences in the intensity of participation, depending on the members' individual levels of expertise. Members with higher expertise are involved in more activities, including those with a higher degree of difficulty and responsibility. "A newcomer's tasks are short and simple, the costs of errors are small, the apprentice has little responsibility for the activity as a whole. A newcomer's task tends to be positioned at the ends of branches of work processes, rather than in the middle of linked work segments" (Lave \& Wenger, 1991, p. 110). In the examples of academic CoPs mentioned above, experts, such as university professors, participate in all activities of complex research projects concentrating on the most difficult parts, whereas novices, such as students, usually take over parts of a lesser extent and difficulty, such as a literature search or statistical data analysis.

Participation is the way in which CoP members gain experience with the community practice, and thereby construct knowledge. In some cases, knowledge is an access requirement to a CoP. In many academic communities, such as universities (Brown, 2001; Rovai, 2002; Thompson \& MacDonald, 2005; Tobbell et al., 2010) or schools (Roth \& Lee, 2006), participation is possible only with a certain minimum of domain knowledge. In some CoPs with more traditional characters, however, such as Indian midwives (Jordan, 1989; Lave \& Wenger, 1991, p. 67), new members may be full novices and have no previous domain knowledge. In any case, interest and personal involvement (e.g., Lave \& Wenger, 1991, p. 79) are considered essential.

In this sense, we build our quantitative model by regarding participation as an indicator of expert status.

\subsection{Expert status}

Identity in CoPs can then be described by various grades of expertise, which can be placed on a continuum from novice to expert, with the so-called regular members (Lave \& Wenger, 1991; Wenger, 1999) in between. Changing identity from beginner to old-timer, and respectively from novice to expert, is an organic aspect of learning in CoPs.

As Wenger asserts (1999, p. 145), "the concept of identity serves as a pivot between the social and the individual". In this sense, identity in the CoP has an individual component, defined by a member's expertise, and a social component, defined by the social interactions in which the CoP member is engaged. A full member possesses superior knowledge and skills, that is to say expertise, and his or her identity also has been negotiated in the CoP to an expert status, so that the full CoP member has access to all the community activities and resources and interacts from a central position with the other CoP members (Tobbell et al., 2010). Because a community practice usually integrates multiple activities (e.g., scientific versus administrative activities in an academic $\mathrm{CoP}$ ), the negotiation of the individual expert status will depend on the type of activity that the individual CoP member carries on (i.e., a scholar will reach a higher expert status than a secretary). 
From the perspective of empirical research, several scholars (e.g., Kienle \& Wessner, 2006) describe expert status as central to the social network, therefore taking into account the number and intensity of relationships with other CoP members (Borgatti, Mehra, Brass, \& Labianca, 2009).

In summary, expert status appears to be a result of participation in the community of practice. Doubtless, there is an influence of expertise on expert status, however this is mediated by participation. Further, we expect the effect of participation on the expert Status to be moderated by activity type.

\subsection{Cultural artifact development}

Generally, the term artifact designates a material as well as an immaterial product of human activity. In many cultural science approaches (particularly from anthropology, archeology, ethnology, and sociology), a cultural artifact has a specific meaning in the community practice. For example, a hammer from the Stone Age is not only a simple tool, but also a reference to operations executed by using it and to more complex activities that include these operations. The stethoscope of a physician is not only an instrument for listening to internal body sounds, but also a reference to diagnostics and medical practice as well as a status symbol distinguishing its bearer from other professionals. Stories are an example of immaterial artifacts; for example, life stories of anonymous alcoholics (Lave \& Wenger, 1991, p. 79) are artifacts developed in the community practice and used by the CoP members to reconstruct their identity as non-drinking alcoholics.

For the aims of this paper, we regard academic websites as a special case of cultural artifacts (Nistor, Schworm, \& Werner, 2012). Web pages usually present the members of research teams along with their research, publication, and teaching experience. Thus, they correspond to Wenger's (1999, p. 108) assertion, that "artifacts are boundary objects, and designing them is designing for participation rather than just use. Connecting the communities involved, understanding practices, and managing boundaries become fundamental design tasks". We regard the presentations of academic practice embodied in websites as parts of the academic discourse. Following Gillespie and Zittoun's (2010) conceptualization of the use of symbolic resources, academic web pages play the role of tools that mediate researchers' acting on and communicating with the academic world. The "leading voices" are the senior scientists, and the younger ones "learn to talk" within the academic discourse, as asserted by Lave and Wenger (1991, p. 109).

Community practices "leave a historical trace of artifacts - physical, linguistic, and symbolic - and of social structures, which constitute and reconstitute the practice over time" (Lave \& Wenger, 1991, p. 58). Moreover, "knowledge within a community of practice and ways of perceiving and manipulating objects characteristic of community practices are encoded in artifacts in ways that can be more or less revealing" (Assmann, 2008; Bereiter, 2002; Lave \& Wenger, 1991, p. 102). Wenger (1999, p. 63) describes this phenomenon as reification of knowledge and claims that the duality of participation and reification is the key to learning processes in the context of CoPs. Through participation, knowledge is both constructed and reified. Conversely, reified knowledge enables further participation. Nistor (2010) proposes that both collaborative knowledge construction (as a central process enabled through participation) and reification are not equally accessible to all community members. Whereas regular members and experts participate, reify their experiences, and continuously construct knowledge, beginners must first go through phases of cognitive apprenticeship before they gain full access to all the community's activities and resources. Consequently, CoP members' contributions to the reification of knowledge and experience appear to be more intensive when their position within the CoP becomes more central. Sustainable artifact development would be impossible without members' access to the CoP resources - a main characteristic of central CoP members. Therefore, members' contributions to the production of cultural artifacts (artifact development) are included in our quantitative CoP model, and we assume that the influence of participation on artifact development is mediated by expert status. This relationship may also be moderated by the activity type.

\section{Deriving a quantitative research model}

In summary, the available CoP literature implies a causal model consisting of the variables expertise (including domain knowledge and experience), participation, expert status, and contribution to cultural artifact development. We regard an individual member's expertise with both of its components as an independent variable that influences participation, which in turn mediates the relationship between expertise and expert status in a CoP. Finally, expert status will have an effect on a CoP member's contribution to artifact development. The influence of participation on expert status will be moderated by activity type. According to this model (depicted in Fig. 1), a novice of the academic CoP will have spent little time in the CoP and have limited domain knowledge, hence limited participation and low expert status, finally bringing a small contribution to the artifact development. Conversely, an expert will have spent a long time in the CoP, will have extensive domain knowledge, intensive participation in the community practice, and thus have a central position in the CoP and bring a significant contribution to artifact development. In academic CoPs, high expertise paired with limited participation (as in the case of temporary professors, CoP newcomers with high expertise, or emeriti, who are CoP oldtimers with high expertise as well) will lead to moderate centrality. These effects will be stronger within scientific activity and weaker among administrative and technical staff.

Nevertheless, Lave and Wenger (1991) advocate a holistic view of community, participation, and identity. This implies a cyclic causal model (e.g., expertise and expert status enable particular forms of participation, which in turn lead to constructing and reifying knowledge, which further extend participation) and complex relationships among the community variables (e.g., Wenger, 1999, p. 154). For the purposes of this research, we simplify this view by cutting the cycles to a momentary record and replacing the longitudinal view of individual evolutions and learning trajectories with a transversal view. We believe that the results may then be cautiously generalized to long-term, cyclic evolutions. 


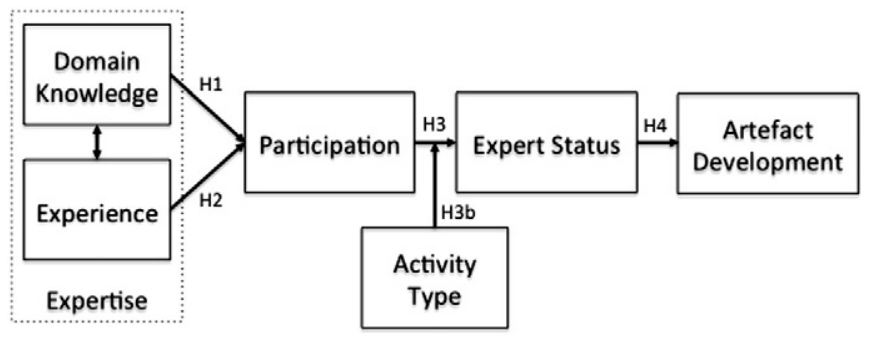

Fig. 1. Causal quantitative model of expertise, participation, expert Status, and contribution to cultural artifact development in CoPs.

\section{Aims of the study and hypotheses}

In correspondence with the research model (Fig. 1) and with a view on the particularities of academic CoPs previously discussed, our research aims at validating the hypothesized quantitative causal CoP model, which implies measuring the community variables, classifying the $\mathrm{CoP}$ members with respect to the measured CoP variables, and verifying the following hypotheses:

H1. Domain knowledge has a positive influence on participation.

H2. Experience has a positive influence on participation.

H3. Participation has a positive influence on expert status.

H3a. The effect of expertise (domain knowledge and experience) on expert status is mediated by participation.

H3b. The effect of participation on expert status is moderated by activity type.

H4. Expert status has a positive influence on artifact development.

H4a. The effect of participation on artifact development is mediated by expert status.

\section{Study 1}

\subsection{Methodology}

\subsubsection{Setting, population and sample}

We conducted a correlation study in two academic CoPs located at universities in Germany and Romania. At German universities, it is usually not possible for academic staff to remain at the same university and move on to professorship positions. Researchers are generally employed for a limited period, usually two to six years, and in this period they have the opportunity to work on a doctoral or professorial dissertation. A professorship can be attained only at another university. Consequently, researchers usually spend short periods of time compared to professors and technical-administrative staff in the same academic community. In contrast, at Romanian universities, long-term positions are more frequent, and faculty members can reach higher positions, including professorships, while staying at the same university.

Both studied CoPs were located at a Faculty of Psychology and Educational Sciences, employing approximately 600 persons at the German university and approximately 300 at the Romanian university. Faculty were predominantly female. The community practice concentrates on university teaching and research, and has a mainly formal, institutionalized character. The artifact development chosen for this study consisted of the design, production, update, and re-design of the websites of the researcher teams. These websites permanently represent academic performance (teaching, research, publications, fund raising etc.) in a current and accurate form, for reasons such as students' orientation, external evaluations, and so forth.

The sample consisted of $N=136$ participants ( $n=69$ in Germany and $n=67$ in Romania) of different expertise levels, belonging to several researcher teams and to a management unit. The complete sample statistics are provided in Table 1.

\subsubsection{Variables and instruments}

The community variables domain knowledge, participation, and artifact development were measured by means of a questionnaire; results are presented in Table 3. These variables proved to have good to very good reliability, as seen in Table 2 . Domain knowledge and intensity of participation were operationalized based on seven dimensions of the academic practice identified by interviewing two full professors. Both sources pointed at academic research, scientific publications, fund raising, university teaching, young researcher support, general coordination and administration, and cooperation with other researcher teams. For domain knowledge, the corresponding items comprised the statement "I have extensive knowledge and skills in the domain X of academic practice" and response options from "totally agree" to "totally disagree". Similarly, for the items of the scale for participation, the participants had to rate the intensity of their professional activity according to the same dimensions ("I used 
Table 1

Sample statistics (RWG $=$ researcher work group; Admin $=$ administration office).

\begin{tabular}{|c|c|c|c|c|c|c|c|c|}
\hline & \multicolumn{3}{|c|}{ German university } & \multicolumn{4}{|c|}{ Romanian university } & \multirow[t]{2}{*}{ Total } \\
\hline & RWG A & RWG B & Admin C & RWG D & RWG E & RWG F & RWG G & \\
\hline Male & 7 & 20 & 0 & 5 & 4 & 3 & 4 & 43 \\
\hline Female & 17 & 22 & 3 & 23 & 8 & 13 & 7 & 93 \\
\hline \multicolumn{9}{|l|}{ Age } \\
\hline Min & 22 & 22 & 49 & 21 & 30 & 26 & 35 & 21 \\
\hline Max & 58 & 72 & 60 & 52 & 54 & 59 & 63 & 72 \\
\hline $\mathrm{M}$ & 35.42 & 35.21 & 53.33 & 30.89 & 39.55 & 35.21 & 48.50 & 36.75 \\
\hline SD & 11.68 & 13.77 & 5.86 & 7.67 & 7.24 & 9.74 & 9.36 & 11.75 \\
\hline Professors & 1 & 4 & 0 & 2 & 3 & 0 & 4 & 14 \\
\hline Researchers and assistant professors & 11 & 15 & 0 & 7 & 7 & 16 & 6 & 62 \\
\hline External lecturers & 6 & 5 & 0 & 0 & 0 & 0 & 0 & 11 \\
\hline Student assistants & 5 & 16 & 0 & 16 & 2 & 0 & 0 & 39 \\
\hline Technical and administrative personnel & 1 & 2 & 3 & 3 & 0 & 0 & 1 & 10 \\
\hline Total & 24 & 42 & 3 & 28 & 12 & 16 & 11 & 136 \\
\hline
\end{tabular}

to contribute actively on a regular basis to the activity of our researcher team in the following domains", with the same response options). The participant's contribution to artifact development was measured by self-rating how much they usually contribute to updating and (re-)designing the website of their own research and teaching (and, respectively, administrative) unit. All ratings were done using five-point Likert scales.

Two further variables were measured in the same questionnaire: Experience was a single figure answering the question "How many years have you been working in the university in the same domain of activity as you are now?". Activity type indicated whether the responder was either involved in scientific activity (professors, assistant professors, researchers, lecturers) or in other kinds of activity (e.g., student assistants, administrative, and technical personnel).

\subsubsection{Procedure}

For the survey, several existing work groups were chosen from the participant institutions, so that the social network consisted of 100-120 members of each academic CoP at the German and the Romanian universities. This target population was sent e-mail invitations to participate in the survey. Two weeks later, the CoP members who had not yet responded were reminded about the study. Two weeks after the second reminder, data collection was closed.

The variable expert status was determined in two steps. First, the participants were given a list of all the persons involved in the study and were asked to rate to what extent they have common activities with each of them. Second, the obtained data served as input for a social network analysis (Borgatti et al., 2009) by using the software UCINET version 6 . All ratings were done by using a five-point Likert scale ( $1=$ no relationship, $5=$ intensive relationship). The expert status of each participant was then extracted

Table 2

Subscales, items, and Cronbach's alpha for the variables domain knowledge, participation, and contribution to artifact development.

\begin{tabular}{|c|c|c|}
\hline Subscales and items & $\begin{array}{l}\text { Cronbach alpha } \\
\text { (German university) }\end{array}$ & $\begin{array}{l}\text { Cronbach alpha } \\
\text { (Romanian university) }\end{array}$ \\
\hline $\begin{array}{l}\text { Domain knowledge } \\
\text { I have much knowledge and skills in the following domains of activity: } \\
\square \text { Academic research } \\
\square \text { Scientific publications } \\
\square \text { Fund raising } \\
\square \text { University teaching } \\
\square \text { Young researcher support } \\
\square \text { General coordination and administration } \\
\square \text { Cooperation with other researcher teams }\end{array}$ & .89 & .78 \\
\hline $\begin{array}{l}\text { Participation } \\
\text { I used to contribute actively on a regular basis to the activity of our } \\
\text { research team in the following domains: } \\
\square \text { Academic research } \\
\square \text { Scientific publications } \\
\square \text { Fund raising } \\
\square \text { University teaching } \\
\square \text { Young researcher support } \\
\square \text { General coordination and administration } \\
\square \text { Cooperation with other research teams }\end{array}$ & .87 & .77 \\
\hline $\begin{array}{l}\text { Contribution to artifact development } \\
\square \text { I used to contribute information to the updating the web pages of our researcher team. } \\
\square \text { I used to contribute to (re-) designing the web pages of our researcher team. }\end{array}$ & .94 & .79 \\
\hline
\end{tabular}


Table 3

Values of the community variables ( $\mathrm{Min}=$ minimum value, $\mathrm{Max}=$ maximum value, $\mathrm{M}=$ mean value, $\mathrm{SD}=\mathrm{standard}$ deviation ).

\begin{tabular}{lcrr}
\hline Variable & Min & Max & M \\
\hline Domain knowledge & 1 & 5 & 2.93 \\
Experience (years) & 1 & 27 & 5.46 \\
Participation & 1 & 5 & 2.88 \\
Expert status & 64 & 188 & 1.10 \\
Artifact development & 1 & 5 & 1.32 \\
\hline
\end{tabular}

as a degree of centrality (in-degree), i.e. the sum of others' ratings in reference to each other participant. Finally, all community data were processed through regression analysis by using IBM SPSS Statistics version 19.

Besides well-known statistical procedures such as regression and variance analysis, cluster analysis was used to classify the participants. In general, cluster analysis builds categories of participants, so that those in the same cluster are more similar to each other than to the participants in other clusters. Applying clustering in the context of this study aims at the empirical verification of theory by comparing the statistically built groups with the categories described in the theory, i.e. experts, intermediates and novices (Dunn, 1974).

\subsection{Results of study 1}

\subsubsection{Community variables}

All model variables had medium mean values (Table 3). Among these, we list several individual values corresponding to different positions within the mainstream trajectory in the CoP hierarchy, such as full professors, research fellows, student assistants, secretaries, and technical staff (Table 4).

\subsubsection{Classification of the CoP members}

The data from the German university were used separately from the Romanian university data as input for two-step cluster analyses using the log-likelihood distance and the Schwarz-Bayes criterion. From the German university, the participants could be classified into three clusters. Cluster D1 ("experts") contains professors and experienced researchers; cluster D2 ("intermediates") contains less experienced researchers and external lecturers as well as administrative and technical personnel; and cluster D3 ("novices") consists of student assistants and tutors. From the Romanian university, the participants were classified into two clusters. Cluster RO1 ("experts") contains professors and experienced researchers; cluster RO2 ("novices") contains less experienced researchers, student assistants, and administrative and technical personnel. The cluster profiles are represented in Table 5 (German participants) and 6 (Romanian participants), as well as Fig. 2a and b. There were significant differences between the clusters for all variables excepting artifact development in the German subsample, as shown by Oneway ANOVA with an $\alpha$ level of .05 (Tables 5 and 6). For the three clusters of German participants, a Tamhane-T2 post-hoc test shows significant differences between all clusters excepting for expert status between clusters D2 and D3.

\subsubsection{Validation of the CoP model}

Given the nearly linear form of the research model and its relatively low complexity, the model was tested by means of a linear regression analysis. All the hypothesized effects (Fig. 1) found evidence in this study, with regression factors ranging from medium to very high. Figs. 3 and 4 display the regression coefficients for the German and Romanian samples, respectively. Fig. 5 shows the regression coefficients for the entire sample. The only effect found to be not significant was that of experience on participation. Participation significantly mediated the positive relationship between domain knowledge and expert status. Only in the German sample did expert status significantly moderate the relationship between participation and artifact development (Fig. 3), whereas in the Romanian sample, participation had a direct effect on artifact development (Fig. 4). Further factors, such as participants' age, had no significant influence on artifact development. In both subsamples, activity type significantly moderated the influence of participation on expert status. In the entire sample, the variance of artifact development could be explained to $17 \%$ ( $23 \%$ in the German sample), the variance of expert status to $22 \%$ ( $28 \%$ in the German sample), and the variance of participation to $82 \%$.

Table 4

Some examples of individual values of the community variables.

\begin{tabular}{|c|c|c|c|c|c|c|}
\hline Position in the academic CoP & Domain knowledge & Experience & Participation & Expert status & Artifact development & Cluster \\
\hline Full professor & 4.86 & 14 & 4.86 & 188 & 4.5 & 1 \\
\hline Research fellow & 4.43 & 8 & 4 & 118 & 3 & 2 \\
\hline Student assistant & 2.29 & 1 & 2 & 125 & 1 & 3 \\
\hline Secretary & 3.57 & 4 & 3.86 & 135 & 4 & 2 \\
\hline Technical staff & 2.14 & 22 & 2.00 & 156 & 1.67 & 1 \\
\hline
\end{tabular}


Table 5

German CoP member cluster profiles (z-standardized mean values), and results of Oneway ANOVA (F-value, significance level, and effect size).

\begin{tabular}{|c|c|c|c|c|c|c|}
\hline \multirow[t]{2}{*}{ Variable } & \multirow{2}{*}{$\begin{array}{l}\text { Cluster D1 } \\
\text { Experts } \\
(n=11)\end{array}$} & \multirow{2}{*}{$\begin{array}{l}\text { Cluster D2 } \\
\text { Intermediates } \\
(\mathrm{n}=39)\end{array}$} & \multirow{2}{*}{$\begin{array}{l}\text { Cluster D3 } \\
\text { Novices } \\
(\mathrm{n}=19)\end{array}$} & \multirow[t]{2}{*}{$F(2,66)$} & \multirow[t]{2}{*}{$p$} & \multirow[t]{2}{*}{$\eta^{2}$} \\
\hline & & & & & & \\
\hline Domain knowledge & 1.18 & 0.02 & -0.86 & 23.907 & .000 & .452 \\
\hline Experience & 1.38 & -0.20 & -0.54 & 23.740 & .000 & .450 \\
\hline Participation & 1.28 & -0.07 & -0.73 & 23.335 & .000 & .446 \\
\hline Expert status & 1.24 & -0.41 & 0.02 & 17.566 & .000 & .377 \\
\hline Artifact development & 0.48 & -0.13 & -0.06 & 1.743 & .184 & .057 \\
\hline
\end{tabular}

\section{Study 2}

\subsection{Methodology}

Similar to Study 1, this study aims at validating the hypothesized quantitative causal CoP model (i.e., measuring the community variables, classifying the CoP members, and verifying the hypotheses of the causal model depicted in Fig. 1).
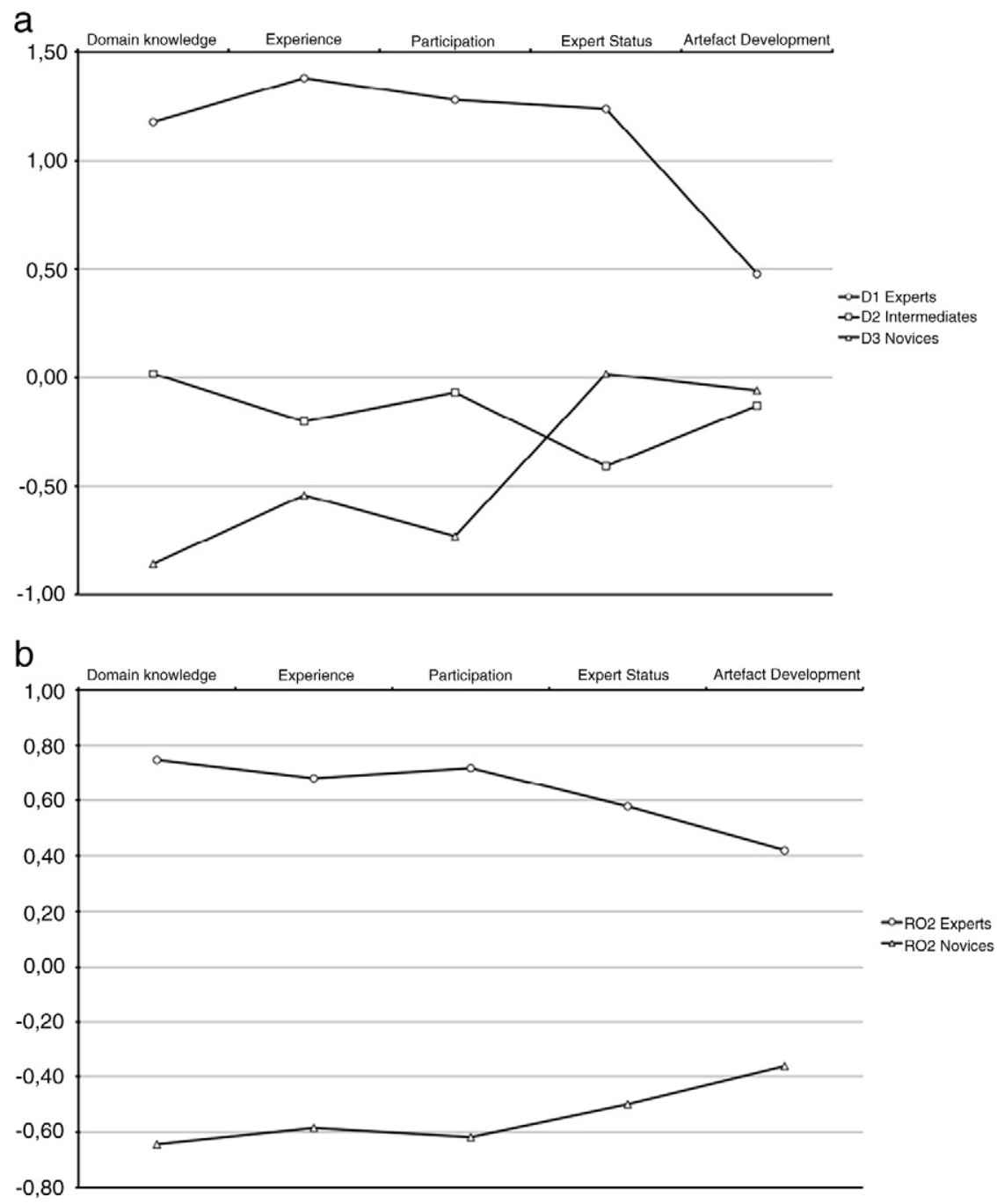

Fig. 2. a: German CoP member cluster profiles (z-standardized mean values of domain knowledge, experience, participation, expert status, and artifact development). b: Romanian CoP member cluster profiles (z-standardized mean values of domain knowledge, experience, participation, expert status, and artifact development). 
Table 6

Romanian CoP member cluster profiles (z-standardized mean values), and results of Oneway ANOVA (F-value, significance level, and effect size).

\begin{tabular}{|c|c|c|c|c|c|}
\hline \multirow[t]{2}{*}{ Variable } & \multirow{2}{*}{$\begin{array}{l}\text { Cluster RO1 } \\
\text { Experts } \\
(n=31)\end{array}$} & \multirow{2}{*}{$\begin{array}{l}\text { Cluster RO2 } \\
\text { Novices } \\
(n=36)\end{array}$} & \multirow[t]{2}{*}{$F(1,65)$} & \multirow[t]{2}{*}{$p$} & \multirow[t]{2}{*}{$\eta^{2}$} \\
\hline & & & & & \\
\hline Domain knowledge & 0.75 & -0.64 & 68.767 & .000 & .514 \\
\hline Experience & 0.68 & -0.59 & 49.823 & .000 & .434 \\
\hline Participation & 0.72 & -0.62 & 44.545 & .000 & .407 \\
\hline Expert status & 0.58 & -0.50 & 21.402 & .000 & .248 \\
\hline Artifact development & 0.42 & -0.36 & 14.665 & .000 & .184 \\
\hline
\end{tabular}

\subsubsection{Population and sample}

Study 2 was conducted in the same Faculty of Psychology and Educational Sciences at a German University as in Study 1. From the same population, different CoPs with different practices emerged. This time, a technology users community was examined, which was focused on the use of IT hardware and software for academic purposes, and which partially overlapped with the community analyzed in Study 1. The IT user community in Study 2 had a partially institutionalized, partially informal character. The institutionalized part of the CoP consisted of IT professionals who built the IT support group of the faculty, employing around 25 persons working in several domains of activity (e.g., telephone hotline, data network, servers, clients and so on). The informal part of the CoP consisted of scientific, technical and administrative staff, and students, as described in Study 1. They had diverse levels of technical expertise, mostly under that of the IT support group. Because of the informal character of this $\mathrm{CoP}$ section, the precise number of CoP members cannot be determined, but only roughly estimated to several hundreds, i.e. most of the approx. 600 faculty employees.

The artifact development considered was the production of written instructions about the use of computers in the frame of academic work, such as how to set up a web browser to gain access to the electronic library of the university. Such instructions were similar to those in hardware or software user manuals; however, they were shorter and not necessarily connected to one another. More information on this practice is provided by Nistor et al. (2012).

The studied sample comprised $\mathrm{N}=72$ participants, of whom 45 were female and 27 male; 58 had non-technical, 4 had technical, and 10 had both technical and non-technical professions (e.g., a diploma in engineering and a doctorate in educational science). From this sample, 62 participants were faculty and 10 were technical staff working for IT support. The 62 faculty comprised 39 researchers ( 9 of these co-administrating the technology infrastructure), 10 secretaries, 10 student assistants, and 3 professors. Participants were between 21 and 62 years of age $(M=34.8, S D=10.7)$.

\subsubsection{Instruments}

For this study, three of the variables were measured by using methods other than those applied in study 1 (Table 7). For domain knowledge, the participants had to self-evaluate their knowledge related to software use (e.g., office software, Internet tools, statistics software), hardware and software installation, network administration, and so forth, using a five-point Likert scale ( $1=$ no knowledge, $5=$ extensive knowledge). For participation, the participants rated how frequently they helped colleagues with activities related to the same dimensions as for domain knowledge. For expert status, the participants evaluated how frequently they helped colleagues from various categories (secretaries and student assistants, among others). For both participation and expert status, the questionnaire used a five-point Likert scale $(1=$ never, $5=$ every day). All other variables (experience, artifact development, and activity type) were measured by using the same instruments as in Study 1 . Generic results are provided in Table 8.

\subsection{Results of Study 2}

\subsubsection{Community variables}

The Study 2 results showed the model variables to have several low or very low values (Table 8). The lowest was the individual contribution to artifact development, where $50 \%$ of the participants do not contribute at all, $28 \%$ contribute seldom, and

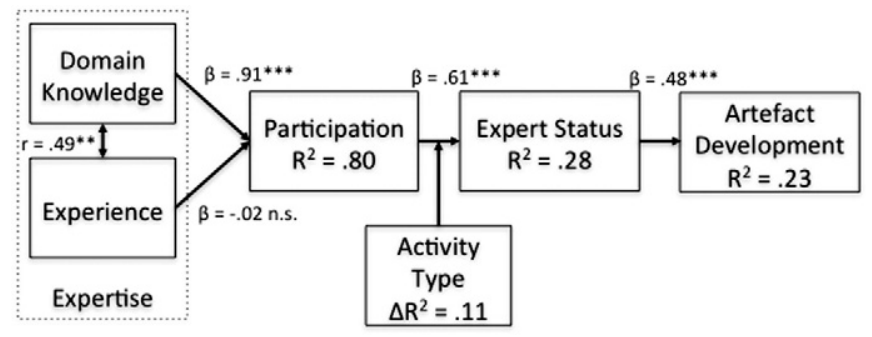

Fig. 3. Regression coefficients $(\beta)$, explained variances $\left(R^{2}\right)$, and correlation factor $(r)$ for the causal model of expertise, participation, expert status, and contribution to cultural artifact development in the German academic $\operatorname{CoP}\left({ }^{* * *} \mathrm{p}<.001,{ }^{* *} \mathrm{p}<.01\right)$. 


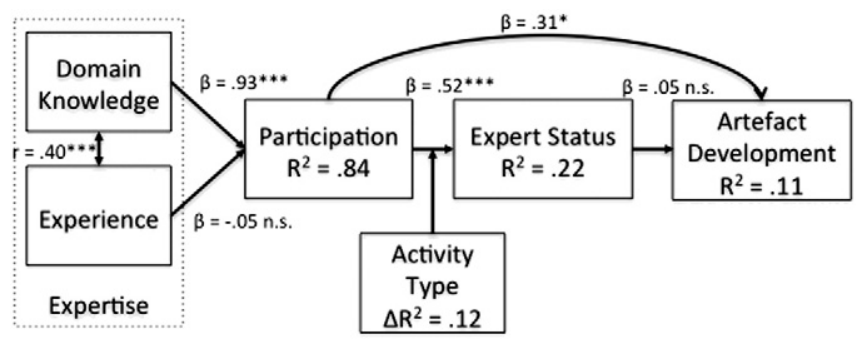

Fig. 4. Regression coefficients $(\beta)$, explained variances $\left(R^{2}\right)$, and correlation factor $(r)$ for the causal model of expertise, participation, expert status and contribution to cultural artifact development in the Romanian academic $\operatorname{CoP}\left({ }^{* * *} \mathrm{p}<.001,{ }^{*} \mathrm{p}<.05\right)$.

$19 \%$ from time to time, and only $3 \%$ contribute frequently with $0 \%$ very frequently. Values also were relatively low for intensity of participation and expert status.

\subsubsection{Classification of the CoP members}

A two-step cluster analysis of the collected data using the log-likelihood distance and the Schwarz-Bayes criterion classified 71 of the 72 participants in two clusters of roughly the same size (Table 9). One person could not be classified because of missing data. Cluster 1 (experts) contains mostly CoP members with mixed (technical and non-technical) professions; cluster 2 (novices) exclusively consists of CoP members with non-technical professions. The cluster profiles are depicted in Fig. 6. There were significant differences between the clusters in the variables domain knowledge, participation, expert status, and contribution to artifact development (Table 9).

\subsubsection{Validation of the CoP model}

Similar to the Study 1 case, the model was validated by means of regression analysis, and most of the effects hypothesized by the research model were found to be significant, with regression factors ranging from medium to high, as displayed in Fig. 7. Again, a hypothesized effect found not significant was that of experience on participation. Participation significantly mediated the relationship between domain knowledge and expert status; that is, domain knowledge has no significant direct effect on expert status (the effect of domain knowledge on expert status variance residuum is $\beta=-.23, \mathrm{p}=.052, \mathrm{R}^{2}=.053$ ). Also, expert status mediated significantly the relationship between participation and artifact development (the effect of participation intensity on artifact development variance residuum is $\beta=.16, \mathrm{p}=.168, \mathrm{R}^{2}=.027$ ). Further factors, such as participants' age, had no significant influence on artifact development. Unlike Study 1, activity type had no significant moderator effect in the model, therefore it was not included in Fig. 7. The variance of artifact development could be explained to $29 \%$, the variance of expert status to $57 \%$, and the variance of participation to $38 \%$ (Fig. 7).

\section{Discussion}

The study at hand provides empirical evidence for a causal CoP model focusing on the individual expert status of a CoP member, and explaining this as being influenced by expertise and participation. Expert status further influences the individual contribution to cultural artifact development. As a preliminary validation, the results of the cluster analysis are in line with the core-periphery structure described unanimously in the CoP literature (Boylan, 2010; Brown, 2001; Fuller et al., 2007; Handley, Sturdy, Fincham, \& Clark, 2006; Jordan, 1989; Kienle \& Wessner, 2006; Lave \& Wenger, 1991; Rovai, 2002; Thompson \& MacDonald, 2005; Wenger, 1999).

The results of the regression analysis provide evidence for the hypothesized quantitative model. Domain knowledge strongly predicts participation, thus confirming the unity of knowledge and participation stated by Lave and Wenger (1991; Wenger, 1999). In Study 1, experience is positively correlated with domain knowledge, as suggested by the deliberate practice concept (Ericsson, 2006). However, experience is not necessarily deliberate practice, and being a CoP member (e.g., a secretary in an

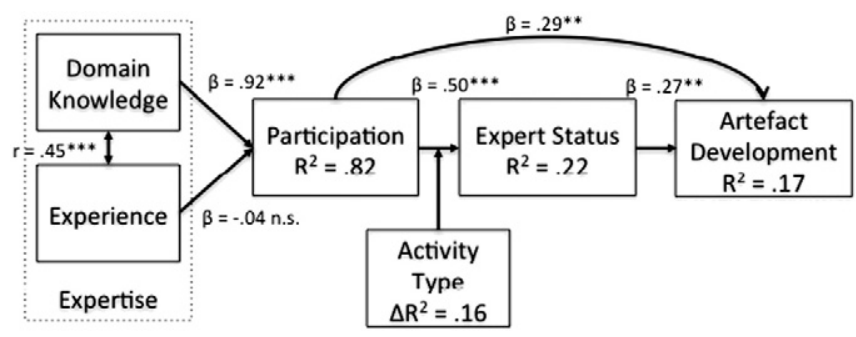

Fig. 5. Regression coefficients $(\beta)$, explained variances $\left(R^{2}\right)$, and correlation factor $(r)$ for the causal model of expertise, participation, expert status and contribution to cultural artifact development in the entire sample $\left({ }^{* * *} \mathrm{p}<.001,{ }^{* *} \mathrm{p}<.01\right)$. 
Table 7

Subscales, items, and Cronbach's alpha for the variables domain knowledge, Participation, and expert status.

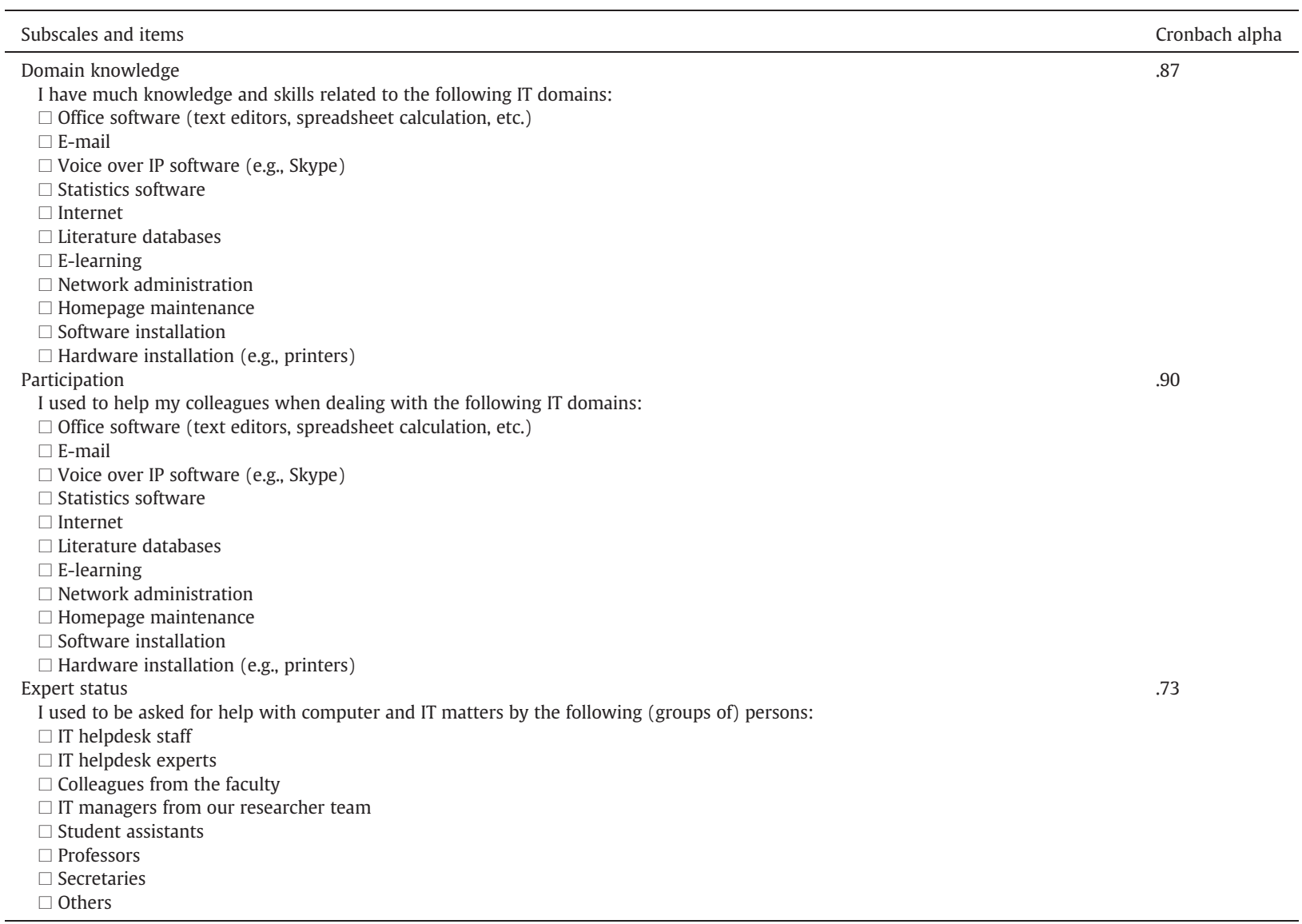

academic CoP) does not automatically lead to expertise in all activity fields of the CoP, notably academic teaching and research. Expertise may indeed be a determinant of participation, which is confirmed by our findings; however, experience has no direct and substantial influence on participation.

Further on, participation mediates the causal relationship between expertise and expert status (with an additional moderating influence of activity type in the case of academic communities). In other words, knowledge can be expressed and applied in a CoP only through participation; in the examined academic CoP, there is no direct influence of domain knowledge on expert identity. This effect has been implied by previous CoP research (Lave \& Wenger, 1991; Skelton, 2012; Tobbell et al., 2010); our studies substantiate it by providing quantitative evidence.

Finally, as assumed by Nistor (2010), expert status has an effect on the participation in the artifact development. However, this may be true only for certain artifacts. In the German academic CoP, web pages appear to play the role of reified knowledge and mediate significant interactions within the CoP and across CoP boundaries. Therefore, central participants take over the contents and design of web pages in order to better control these interactions. The Romanian academic CoP, in contrast, probably has more direct interactions and fewer interactions mediated by web pages. Web pages nevertheless may be an object of the community practice, however less important for the central CoP members. This difference is reflected in our findings in terms of different regression coefficients and explained variance of artifact development. Cultural differences may be a further explanation for this.

Table 8

Values of the CoP model variables (Min = minimum value, Max = maximum value, $\mathrm{M}=$ mean value, $\mathrm{SD}=\mathrm{standard}$ deviation).

\begin{tabular}{llcr}
\hline Variable & Min & Max & M \\
\hline Domain knowledge & 1.00 & 4.82 & 3.45 \\
Experience (years) & 0 & 20 & 5.32 \\
Participation & 1.00 & 4.09 & 2.22 \\
Expert status & 1.00 & 4.57 & .83 \\
Artifact development & 1 & 4 & .77 \\
\end{tabular}


Table 9

CoP member cluster profiles for study 2 (z-standardized mean values), and results of Oneway ANOVA (F-value, significance level, and effect size).

\begin{tabular}{|c|c|c|c|c|c|}
\hline \multirow[t]{2}{*}{ Variable } & \multirow{2}{*}{$\begin{array}{l}\text { Cluster } 1 \\
\text { Experts } \\
(n=33)\end{array}$} & \multirow{2}{*}{$\begin{array}{l}\text { Cluster } 2 \\
\text { Novices } \\
(\mathrm{n}=39)\end{array}$} & \multirow[t]{2}{*}{$F(1,70)$} & \multirow[t]{2}{*}{$p$} & \multirow[t]{2}{*}{$\eta^{2}$} \\
\hline & & & & & \\
\hline Domain knowledge & .28 & -.18 & 4.124 & .046 & 0.056 \\
\hline Experience & -.04 & .04 & 0.105 & .747 & 0.002 \\
\hline Participation & .43 & -.42 & 16.098 & .000 & 0.189 \\
\hline Expert status & .53 & -.48 & 24.159 & .000 & 0.259 \\
\hline Artifact development & .32 & -.35 & 9.775 & .003 & 0.124 \\
\hline Sex & 26 & 0 & & & \\
\hline Male & 7 & 39 & & & \\
\hline Female & & & & & \\
\hline
\end{tabular}

In a broader view, the proposed quantitative model represents a causal chain leading from domain knowledge to knowledge reification (i.e., artifact development). This is where the cycle may close: reified knowledge and artifacts support CoP members' domain knowledge and sustain their future participation on a higher level, as Wenger (1999) emphasizes. This is also where we can return from the simplified, transversal view to the original, longitudinal view, and thus reconstruct the holistic view advocated by Lave and Wenger (1991).

Some differences between the academic and the IT users communities emerged, especially concerning the regression coefficients and the explained variances of domain knowledge, participation, and expert status. Study 2 (IT users CoP) shows a weaker effect of domain knowledge on participation, thus explaining a smaller part of the variance of participation than in study 1 (academic CoP). Since the similarities of the measurement methods of domain knowledge and participation are greater in Study 1 than in Study 2, the results of Study 2 may be regarded as more realistic, and the results of Study 1 may be inflated by common methods bias (see below; Podsakoff, MacKenzie, Lee, \& Podsakoff, 2003). Further on, Study 2 explained a larger part of the expert status variance than Study 1. In the academic CoP (Study 1), expert status was determined by means of a social network analysis where the involved social network was clearly limited to the study sample; for Study 2, the operationalization chosen was potentially non-restrictive.

The proposed model allows the identification of discrepancies between expertise and expert status in CoPs. Assuming that expertise and expert status should ideally have similar levels, a CoP member's expert status that is lower than his or her actual expertise would suggest that the CoP member is not sufficiently integrated into the community. Hence, the expert's centrality in the social network would have to be increased, which could easily be done by an appropriate introduction of the expert newcomer. Additional activities could be created to facilitate knowledge sharing and interaction with the expert. Conversely, a CoP member's individual expert status that is higher than his or her expertise might suggest an overall lack of expertise in the network. In this case, knowledge management measures, such as training the CoP members or hiring experts, are recommended. In technology-based CoPs (Brown, 2001; Stewart, 2010; Thompson \& MacDonald, 2005), this study may stimulate the development of online tools that monitor the concordance (or discrepancy) of expertise and expert status in CoPs, and thus improve the e-learning experience for all participants.

This study has several limitations. First, the transversal measures offer a fair approximation of the CoP processes, but may distort the image of individual learning trajectories (Wenger, 1999) or learning identities (Skelton, 2012; Tobbell et al., 2010). Not every CoP member follows a linear learning trajectory from novice to expert, as suggested by Lave and Wenger (1991) in their

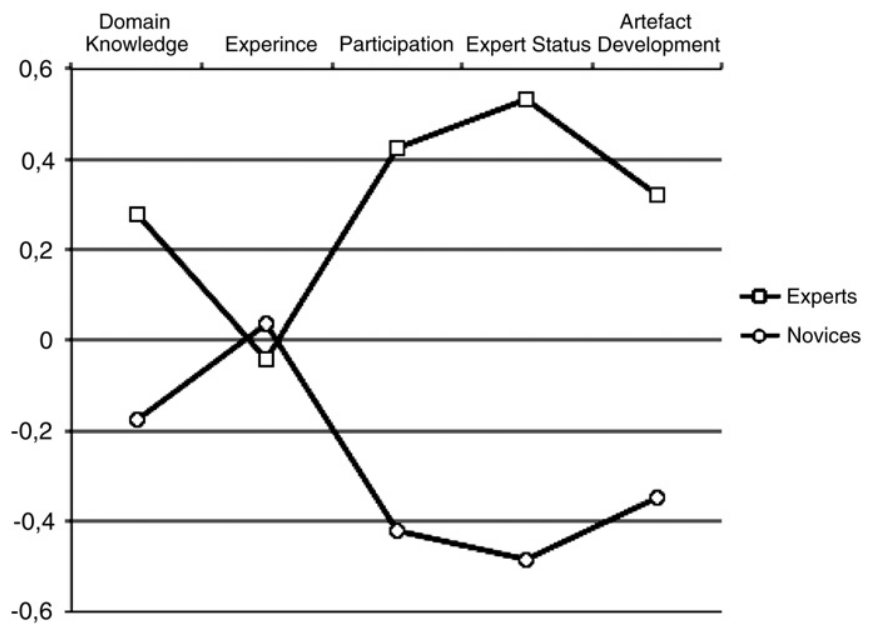

Fig. 6. Cluster profiles for study 2 (z-standardized mean values of domain knowledge, experience, participation, expert status, and artifact development). 


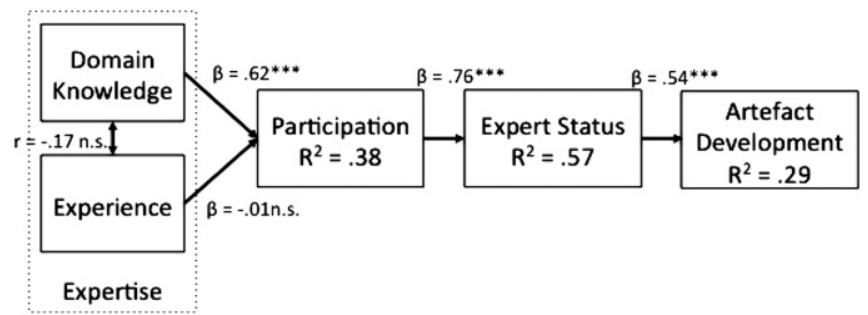

Fig. 7. Regression coefficients $(\beta)$, explained variances $\left(R^{2}\right)$ and correlation factor $(r)$ for the causal model of expertise, participation, expert status and contribution to cultural artifact development $\left({ }^{* * *} \mathrm{p}<.001\right)$.

first approach to CoPs. In this respect, more recent literature emphasizes the complexity of the learning trajectories in academic CoPs (Boylan, 2010; Handley et al., 2006), as well as in workplace CoPs (Fuller, Hodkinson, Hodkinson, \& Unwin, 2005). Future research should thus include longitudinal studies.

Second, community in this study was regarded in a rather simplistic manner. Several dimensions were reduced to a limited number of aspects (e.g., much versus little domain knowledge on certain topics, high versus low intensity of participation, high versus low expert status). This simplification might be less problematic when considering mainstream trajectories in academic communities (Visscher \& Witziers, 2004), but it may oversimplify specific cases such as those of emeriti or temporary professors.

Third, the study is based entirely on a questionnaire survey. Besides subjectivity, several correlations and especially the effect of domain knowledge on participation may be inflated by common method bias (Podsakoff et al., 2003). However, the different operationalization applied in the second study can be seen as evidence for the validity of the correlations. Nevertheless, future research should include more behavioral data, such as that resulting from interaction analysis.

In summary, the results of Study 1 provide evidence for a quantitative model of communities of practice, mainly linking the concepts of expertise, participation, expert status and the contribution to artifact production. These results were largely replicated in Study 2, which uses another domain.

\section{Acknowledgment}

The authors would like to thank Brigitte Jordan for the inspiring correspondence on communities of practice; Karsten Stegmann for his helpful suggestions on the research model; Anna Maria August, Anamaria Dorgo and Monika Schustek for their contributions to data collection; and Jan Oliver Heymann for his contribution to data processing.

\section{References}

Assmann, J. (2008). Communicative and cultural memory. In A. Erll, \& A. Nünning (Eds.), Cultural memory studies. An international and interdisciplinary handbook (pp. 109-118). Berlin: Walter de Gruyter.

Bereiter, C. (2002). Education and mind in the knowledge age. Mahwah, NJ: Lawrence Erlbaum.

Bonsen, M., \& Rolff, H. G. (2006). Professionelle Lerngemeinschaften von Lehrerinnen und Lehrern. Zeitschrift für Pädagogik, 52(2), $167-184$.

Borgatti, S. P., Mehra, A., Brass, D. J., \& Labianca, G. (2009). Network analysis in the social sciences. Science, 323, $892-895$.

Boylan, M. (2010). Ecologies of participation in school classrooms. Teaching and Teacher Education, 26(1), 61-70.

Brown, R. E. (2001). The process of community-building in distance learning classes. Journal of Asynchronous Learning Networks, 5(2), $18-35$.

Dunn, J. (1974). Well separated clusters and optimal fuzzy partitions. Journal of Cybernetics, 4(1), 95-104.

Engeström, Y., \& Sannino, A. (2010). Studies of expansive learning: Foundations, findings and future challenges. Educational Research Review, 5(1), 1-24.

Ericsson, K. A. (2006). The influence of experience and deliberate practice on the development of superior expert performance. In K. A. Ericsson, N. Charness, P. Feltovich, \& R. R. Hoffman (Eds.), Cambridge handbook of expertise and expert performance (pp. 685-706). Cambridge, UK: Cambridge University Press.

Fuller, A. (2007). Critiquing theories of learning and communities of practice. In J. Hughes, N. Jewson, \& L. Unwin (Eds.), Communities of practice. Critical perspectives. (pp. 17-29) London: Routledge.

Fuller, A., Hodkinson, H., Hodkinson, P., \& Unwin, L. (2005). Learning as peripheral participation in communities of practice: A reassessment of key concepts in workplace learning. British Educational Research Journal, 31(1), 49-68.

Fuller, A., Unwin, L., Felstead, A., Jewson, N., \& Kakavelakis, K. (2007). Creating and using knowledge: An analysis of the differentiated nature of workplace learning environments. British Educational Research Journal, 33(5), 743-759.

Gillespie, A., \& Zittoun, T. (2010). Using resources: Conceptualizing the mediation and reflective use of tools and signs. Culture E Psychology, 16(1), 37-62.

Handley, K., Sturdy, A., Fincham, R., \& Clark, T. (2006). Within and beyond communities of practice: Making sense of learning through participation, identity and practice. Journal of Management Studies, 43(3), 641-653.

Jordan, B. (1989). Cosmopolitical obstetrics: Some insights from the training of traditional midwives. Social Science E' Medicine, 28(9), 925-944.

Kienle, A., \& Wessner, M. (2006). Analyzing and cultivating scientific communities of practice. International Journal of Web Based Communities, 2(4), 377-393.

Lave, J., \& Wenger, E. (1991). Situated learning. Legitimate peripheral participation. Cambridge, UK: University Press.

Nistor, N. (2010). Knowledge communities in the classroom of the future. In K. Mäkitalo-Siegl, F. Kaplan, J. Zottmann, \& F. Fischer (Eds.), Classroom of the future. Orchestrating collaborative spaces. (pp. 163-180) Rotterdam: Sense.

Nistor, N., Schworm, S., \& Werner, M. (2012). Online help-seeking in communities of practice: Modeling the acceptance of conceptual artifacts. Computers in Education, 59(2), 774-784

Paavola, S., Lipponen, L., \& Hakkarainen, K. (2004). Models of innovative knowledge communities and three metaphors of learning. Review of Educational Research, 74(4), 557-576.

Podsakoff, P. M., MacKenzie, S. B., Lee, J. Y., \& Podsakoff, N. P. (2003). Common method bias in behavioral research: A critical review of the literature and recommended remedies. Journal of Applied Psychology, 88(5), 879-903.

Roth, W. M., \& Lee, Y. J. (2006). Contradictions in theorizing and implementing communities in education. Educational Research Review, 1(1), 27-40.

Rovai, A. P. (2002). A preliminary look at the structural differences of higher education classroom communities in traditional and ALN courses. Journal of Asynchronous Learning Networks, 6(1), 41-56. 
Skelton, A. (2012). Teacher identities in a research-led institution: In the ascendancy or on the retreat? British Educational Research Journal, 38(1), 23-39.

Stewart, T. (2010). Editorial: Online communities. Behaviour \& Information Technology, 29(6), 555-556.

Thompson, T. L., \& MacDonald, C. J. (2005). Community building, emergent design and expecting the unexpected: Creating a quality eLearning experience. The Internet and Higher Education, 8(3), 233-249.

Tobbell, J., O'Donnell, V., \& Zammit, M. (2010). Exploring transition to postgraduate study: Shifting identities in interaction with communities, practice and participation. British Educational Research Journal, 36(2), 261-278.

Visscher, A. J., \& Witziers, B. (2004). Subject departments as professional communities? British Educational Research Journal, 30(6), 785-800.

Wenger, E. (1999). Communities of practice. Learning, meaning, and identity. Cambridge, UK: University Press. 